\title{
Is Bitcoin a Commodity? On Price Jumps, Demand Shocks, and Certainty of Supply
}

\author{
Marc Gronwald*
}

February 2019

\begin{abstract}
This paper discusses how similar Bitcoin is to a commodity. The application of a number of both linear and non-linear GARCH models indicates that the role of extreme price movements is particularly pronounced. GARCH models with student- $t$ innovations as well as combined jump-GARCH models are among the models with the best fit. The role of large movements is found to be stronger in the Bitcoin market than in the markets for crude oil and gold. As Bitcoin shares with these exhaustible resource commodities characteristics such as the fixed supply, the analysis of Bitcoin prices can generally learn from the analysis of exhaustible resource commodities. However, whereas the short-run supply of gold and oil are uncertain, there are no uncertainties on the Bitcoin supply-side. Thus, the observed movements of Bitcoin prices can be interpreted as results of Bitcoin demand shocks.

Keywords: Bitcoins, GARCH, Jump models, Bitcoin demand shocks JEL-Classification: C12, C22, C58, G12
\end{abstract}

\footnotetext{
* University of Aberdeen Business School, Aberdeen Centre for Research in Energy Economics and Finance, CESifo and ifo Institute. Mailing address: University of Aberdeen Business School, Edward Wright Building Block B, Dunbar Street, Aberdeen, AB24 3QY, United Kingdom. Email: mgronwald@abdn.ac.uk. Phone: 00441224 272204.The author gratefully acknowledges useful comments by Beat Hintermann and Stefan Trueck as well as seminar and conference participants at the Society for Computational Economics Annual Conference 2016, the CESifo Area Conference for Macro, Money and International Finance, University of Dundee, University of East Anglia, University College Dublin, and Macquarie University Sydney. Furthermore, the author is indebted to Sandrine Ngo for motivating me to study the economics of Bitcoins.
} 


\section{INTRODUCTION}

The cryptocurrency Bitcoin emerged in 2008, created with the aim to make possible online payments without involvement of a financial institution or other third parties; see Nakamoto (2008). Bitcoin is the most popular cryptocurrency; others such as Etherum, Litecoin and Ripple emerged subsequently. Among the questions debated in both the general public and in academia is whether Bitcoin is indeed a currency or "merely" a speculative asset. What is more, the emergence of cryptocurrencies also revived the debate on private money and currency competition, and, finally, some central banks consider the introduction of so-called central bank digital currencies.

This paper contributes to a steadily growing empirical literature on Bitcoin prices by applying a number of both linear and non-linear GARCH models. ${ }^{1}$ As the particular focus is on the role of extreme price movements, Chan and Maheu's (2002) jump-GARCH model takes centre stage; in addition, a benchmark standard GARCH model, Glosten et al.'s (1993) TGARCH, Nelson's (1991) EGARCH are employed.

The empirical analysis shows that extreme price movements play a particularly strong role: the standard GARCH model with student- $t$ innovations as well as the combined jump-GARCH model perform particularly well. These results are anticipated insofar as the Bitcoin market only recently emerged and is, thus, still in an immature state. In this type of environment, individual events not surprisingly have a larger impact on prices than in more mature markets. Worth emphasising is that extreme

\footnotetext{
${ }^{1}$ The Bitcoin price used in this paper is the Bitcoin USD exchange rate.
} 
price movements are found to play a larger role in the Bitcoin market than in the markets for crude oil and the gold - exhaustible resource commodities Bitcoin shares some characteristics with: the total number of Bitcoins is fixed and the number of Bitcoins in circulation is known with certainty. This resembles the exhaustibility of oil and gold. Various authors state that Bitcoin is not a currency but some sort of a speculative investment. This type of conclusion is vague insofar as it only rules out one possible interpretation without offering a clear alternative. This paper's emphasis on the similarities between Bitcoin and exhaustible resource commodities remedies this as for those established pricing theories and a general a theoretical understanding exists. Thus, the analysis of Bitoin prices should learn from analyses of exhaustible resource commodities. There are, however, some important differences: While the markets for crude oil and gold are characterised by considerable short-run supply-side uncertainty - supply shocks, often sparked by political events, surprise discoveries and technological developments occur very frequently - no uncertainty of this type exists on the supply-side of Bitcoin. Thus, the observed price fluctuations of Bitcoin can be interpreted as demand shocks. This is an alternative way to phrase Ali et al.'s (2014) assertion that "digital currencies have meaning only to the extent that participants agree that they have meaning."

\section{Related Literature}

The extant empirical literature this paper contributes to can be divided into six categories: first, a large number of papers is testing the Efficient Mar- 
ket Hypothesis (EMH) in the Bitcoin market. The early contribution by Urquhart (2016) applies a number of non-linearity tests and finds that Bitcoin markets are inefficient. More recent contributions such as Cheah et al. (2018) and Khuntia and Pattanayak (2018) deal with long memory and the Adaptive Market Hypothesis (AMH), respectively. While the former finds clear evidence of long-memory, the latter show that market efficiency evolves with time; thus, the AMH is validated. A second stream of literature analyses Bitcoin from an investment perspective. Dyhrberg (2016) states that Bitcoins' hedging capabilities are comparable to those of gold. Dyhrberg et al.'s (2018) analysis of the investibility of Bitcoin finds that Bitcoin is highly investible. Henrique and Sadorsky (2018) show that Bitcoin can replace gold in an investment portfolio and state that risk-averse investors would be willing to "pay a high performance fee to switch from a portfolio with gold to a portfolio with Bitcoin". Third, a number of papers deal with statistical modelling of Bitcoin prices in a more general sense. Katsiampa (2017) estimates volatility using a number of GARCH models. Baur et al. (2018) find that Bitcoin is uncorrelated with with traditional asset classes; based on an analysis of transaction data, they, furthermore, conclude that Bitcoin is mainly used as speculative investment. Phillip et al.'s (2018) "new look at cryptocurrencies" reveals that they are characterised by predictable patterns with mostly oscillating persistence. With the emergence of additional cryptocurrencies, fourth, the obvious question of volatility spillover between cryptocurrency markets arose. Yi at al. (2018) show that volatility connectedness among eight cryptocurrencies fluctuates cyclically. In addition, they find that Bitcoin is not the dominant player in this regard. Fifth, Urquhart 
(2018) as well as Shen et al. (2019) deal with how to measure investors attention. While the former relies on search data from Google trends, the latter argues that the number of tweets on Twitter is the preferable measure. Both papers find that investor attention is a significant driver of e.g. next day's trading volume. Finally, motivated by the sharp increases of Bitcoin prices, papers such as Cheah and Fry (2015) and Corbet et al (2018) test for Bitcoin bubbles. This type of papers usually finds evidence of those bubbles; in addition, they provide start and end dates of the bubble periods. This result, however, is questionable insofar as Bitcoin does not have an intrinsic value. In addition to these empirical studies, the emergence of Bitcoin also revived the discussion on private money and currency competition. While Dowd and Hutchinson (2015) are generally very enthusiastic about these prospects, Sanches (2016) is more sceptical: His paper highlights the inherent instability of private money. ${ }^{2}$ The emergence of Bitcoin, finally, also motivated some central banks to discuss the possibility of issuing so-called central bank digital currency (CBDC) ${ }^{3}$ CBDC would combine the convenience and advantages of digital currencies with the stability of central bank issues currency. Among the main motivations discussed by Engert and Fung (2017) are the promotion of financial inclusion and a reduction in the lower bound on interest rates. The macroeconomic effects of CBDC, however, are clearly insufficiently understood. Recent analyses including Keister and

\footnotetext{
${ }^{2}$ In a recent working paper, Fernandez-Villaverde and Sanches (2016) investigate if currency competition in the spirit of Hayek (1976) can work. For a non-technical summary of this discussion, see Sanches (2018).

${ }^{3}$ Please note that currently no peer-reviewed research in this area exists. All contributions are either in working paper stage or published in central bank discussion paper series.
} 
Sanches (2018) and Kumhof and Noone (2018) are mainly concerned about effects on bank funding, credit and liquidity provision, and crowding out of bank deposits. A number of important design principles are under discussion, in particular whether or not the CBDC pays interest and how widely it circulates. Camara et al. (2018), finally, argue, from a Latin American perspective, that developing countries benefit more from CBDC than developed countries. Regardless of whether or not Bitcoin and other cryptocurrencies ultimately fail - without the emergence of those a discussion about central bank digital currencies would not exist.

\section{Data And Empirical Methods}

Bitcoins and other cryptocurrencies are traded on various exchanges. This paper uses two Bitcoin price series from two different exchanges: first, Mt.Gox, until its shutdown the most liquid Bitcoin exchange, and second, Bitstamp. Bitstamp is among the exchanges with the highest market share. The periods of observation are 7/02/2011 - 2/24/2014 and 9/16/2011 $1 / 25 / 2019$, respectively; data frequency is daily, and log-returns of the prices are used. ${ }^{4}$ Figure 1 vividly illustrates the presence of volatility clusters as well as extreme price movements. ${ }^{5}$

The focus of this paper is on those extreme price movements. The so-

\footnotetext{
${ }^{4}$ Data source: www.bitcoincharts.com.

${ }^{5} \mathrm{~A}$ number of recent papers also point out that certain commodity prices are not only characterized by conditional heteroscedastcity but also by jumps: Gronwald (2012) finds evidence of jumps in crude oil prices, Sanin et al (2015) in European carbon prices. These markets are generally considered "political" markets subject to various types of influences. The European carbon market, in addition, is also a newly established market. Jumps in commodity prices are generally considered reflecting reactions of prices to surprising news; see e.g. Jorion (1988).
} 

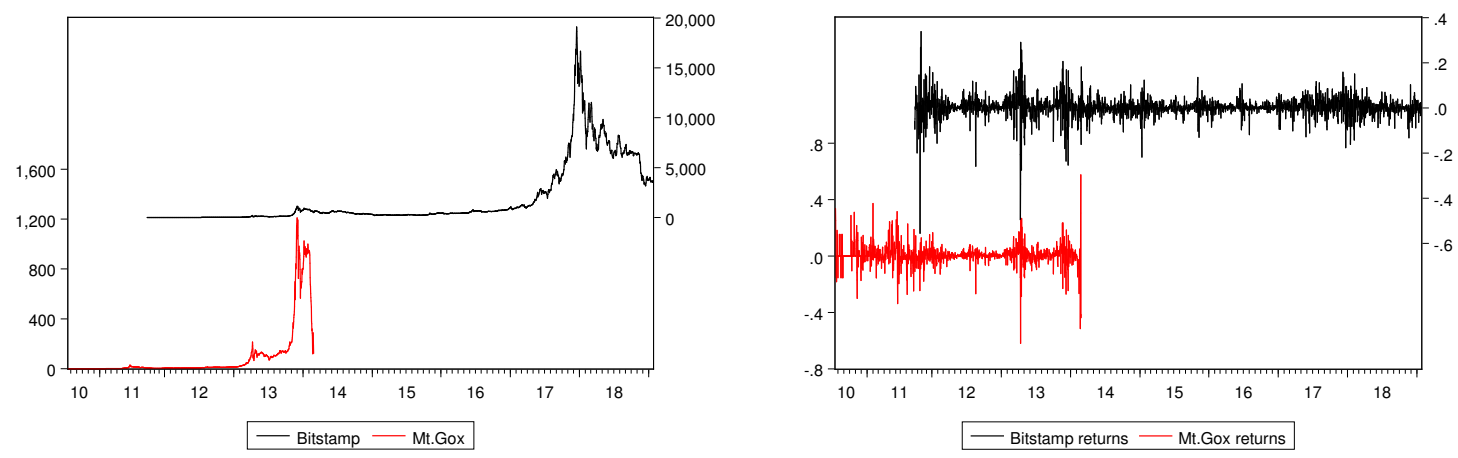

Figure 1: Bitcoin prices - levels and returns

called autoregressive jump-intensity GARCH model proposed by Chan and Maheu (2002) is used in order to analyse the role of extreme price movements in the Bitcoin market. A standard $\operatorname{GARCH}(1,1)$ model serves as the benchmark; Gaussian as well as student- $t$ innovations are considered. In addition a number of extensions are used: Integrated GARCH (IGARCH) proposed by Engle and Bollerslev (1986), Glosten et al.'s (1993) TGARCH, and EGARCH as proposed by Nelson (1991). ${ }^{6}$ These models allow one to capture features such as asymmetric response to negative and positive news as well as leverage effects. ${ }^{7}$

\section{Results}

Table 1 presents both the parameter estimates of the applied GARCH models and compares their goodness-of-fit. It is evident that the best performing

\footnotetext{
${ }^{6}$ The number of autoregressive parameters is selected using standard Information Criteria. All extensions use Gaussian innovations only.

${ }^{7}$ As all these methods are well-established standard methods, no detailed discussion of these models is provided. The interested reader is referred to the original papers or the online appendix.
} 
model is GARCH with student- $t$ innovations, followed by the jump-GARCH models. The latter cannot outperform the former but still provide a considerable increase of the goodness-of-fit. The parameter estimates overall confirm these results: all but one jump-parameter are statistically different from zero. The table also shows that leverage effects do not seem to play a considerable role and that the parameter restriction implied in the IGARCH model is not useful. Finally, the GARCH parameters of all models under consideration - the notable exception are the combined jump-GARCH models - are in sum larger than 1 . Thus, the shocks in these GARCH models would be persistent; a finding attributable to the immaturity of the Bitcoin market.

The jump-GARCH model estimates deserve some further discussion: Figure 2 presents both the estimated time-varying jump intensity and the jump-induced variance. It is evident that higher jump-intensities are more frequent in 2011-2013 as well as in 2017-2018; between these periods, price behavior of Bitcoin was quieter, in relative terms at least. The largest peaks occur during the fourth quarter of 2011, the third quarter of 2012, the second quarter 2013. In the beginning of 2014, Mt.Gox prices are marked by particularly large jumps related to the market turbulences prior to its shutdown. Bitstamp prices in 2017-2018 are characterised by extended periods of high jump intensity. The variance decomposition, furthermore, shows that the share of variance induced by jumps fluctuates around 60\%. Pronounced decreases occur a number of times; mostly at the same time large peaks of the jump-intensity occur. The share of jump-induced variance drops to about $15-30 \%$ in earlier periods; later this measure is always above $20 \%$. 


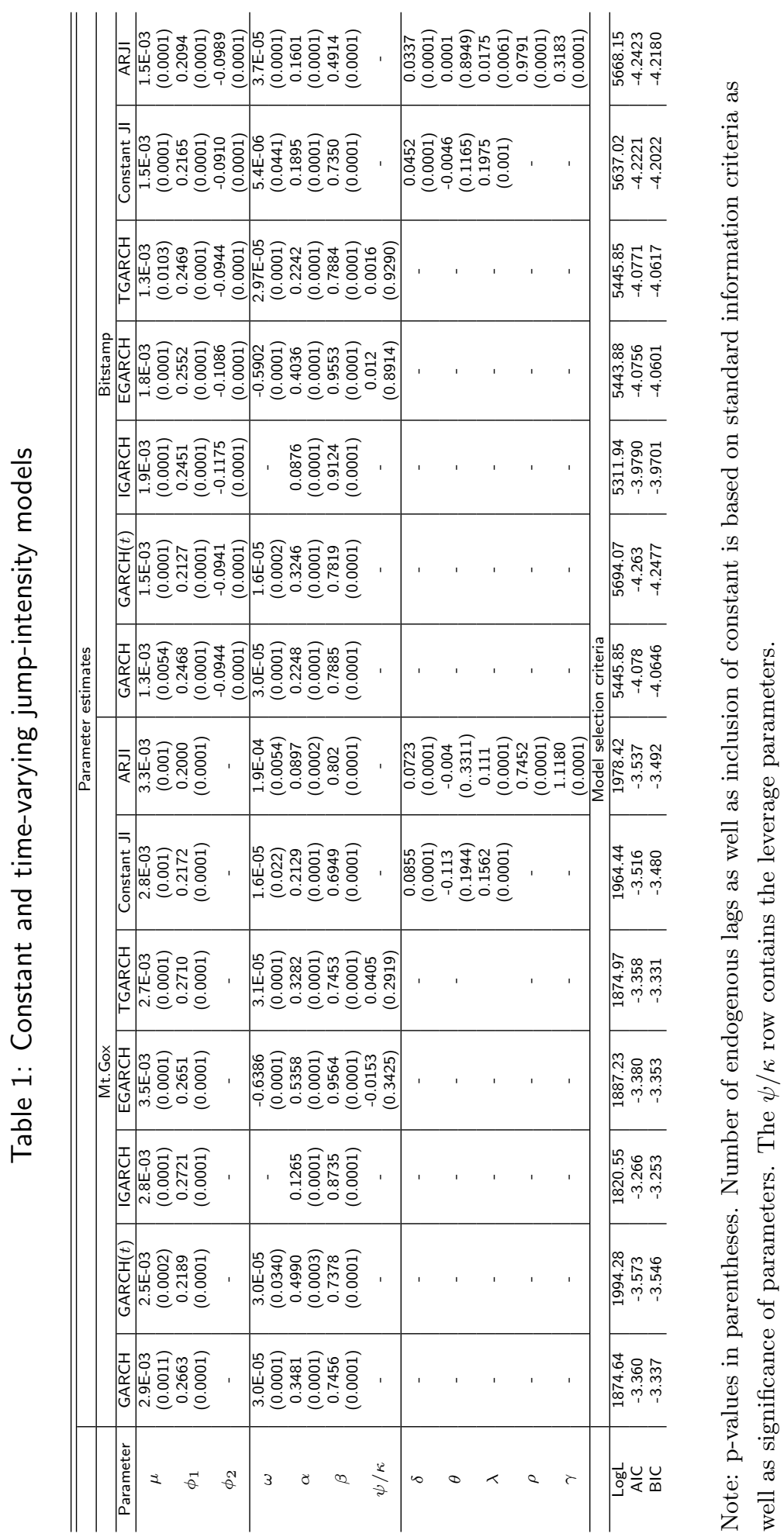



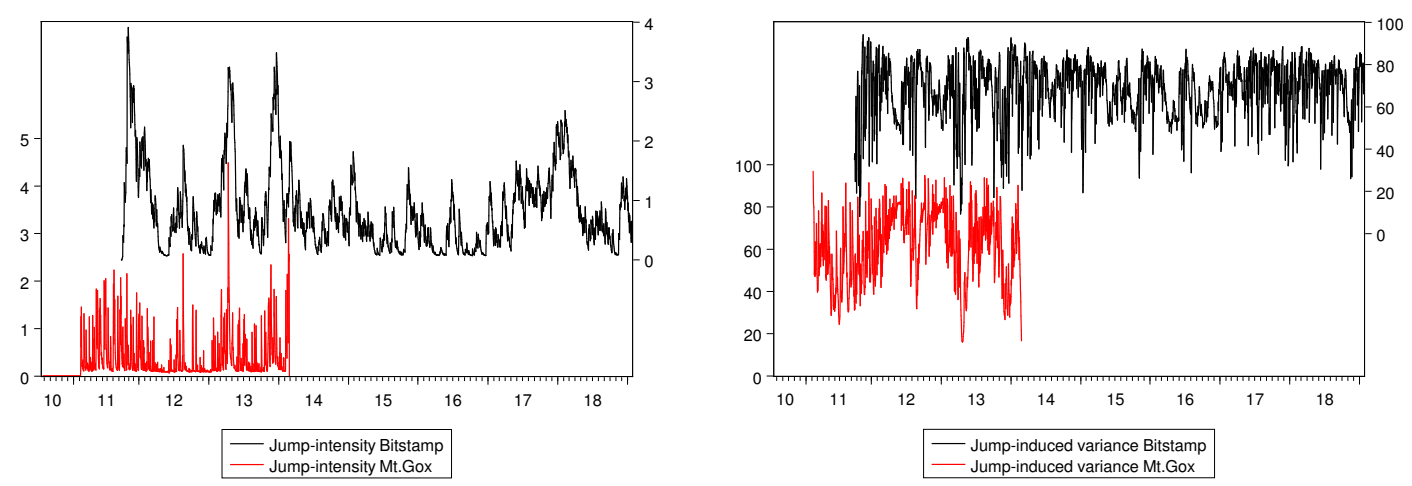

Figure 2: Jump intensities and jump-induced variance

Although these findings, at first glance, seem to contradict each other, there is a simple explanation: in the aftermath of the extreme movements the volatility is generally higher, with a larger share of volatility captured by the GARCH component. ${ }^{8}$

These results gain in importance when compared to the estimation of the same set of models using both crude oil and gold prices; see Figure $3 .^{9}$ It is evident that the share of oil price variance induced by jumps fluctuates around $40 \% .^{10}$ Thus, this measure is considerably lower than for the Bitcoin prices. Moreover, in the aftermath of extreme price movements associated with the OPEC collapse 1986, the Gulf War 1991, and the oil price record high of 2008, this share drops drastically to just $5-10 \%$ - also much lower than the values found for the Bitcoin market. After the oil price decline in 2014, the share is found be relatively low as well. Thus, during this extraordinary period with a high degree of uncertainty, singular events play

\footnotetext{
${ }^{8}$ Gronwald (2012) finds a similar pattern for the crude oil market.

${ }^{9}$ Detailed estimation results can be found in the Appendix.

${ }^{10}$ This result is very similar to Gronwald (2012).
} 

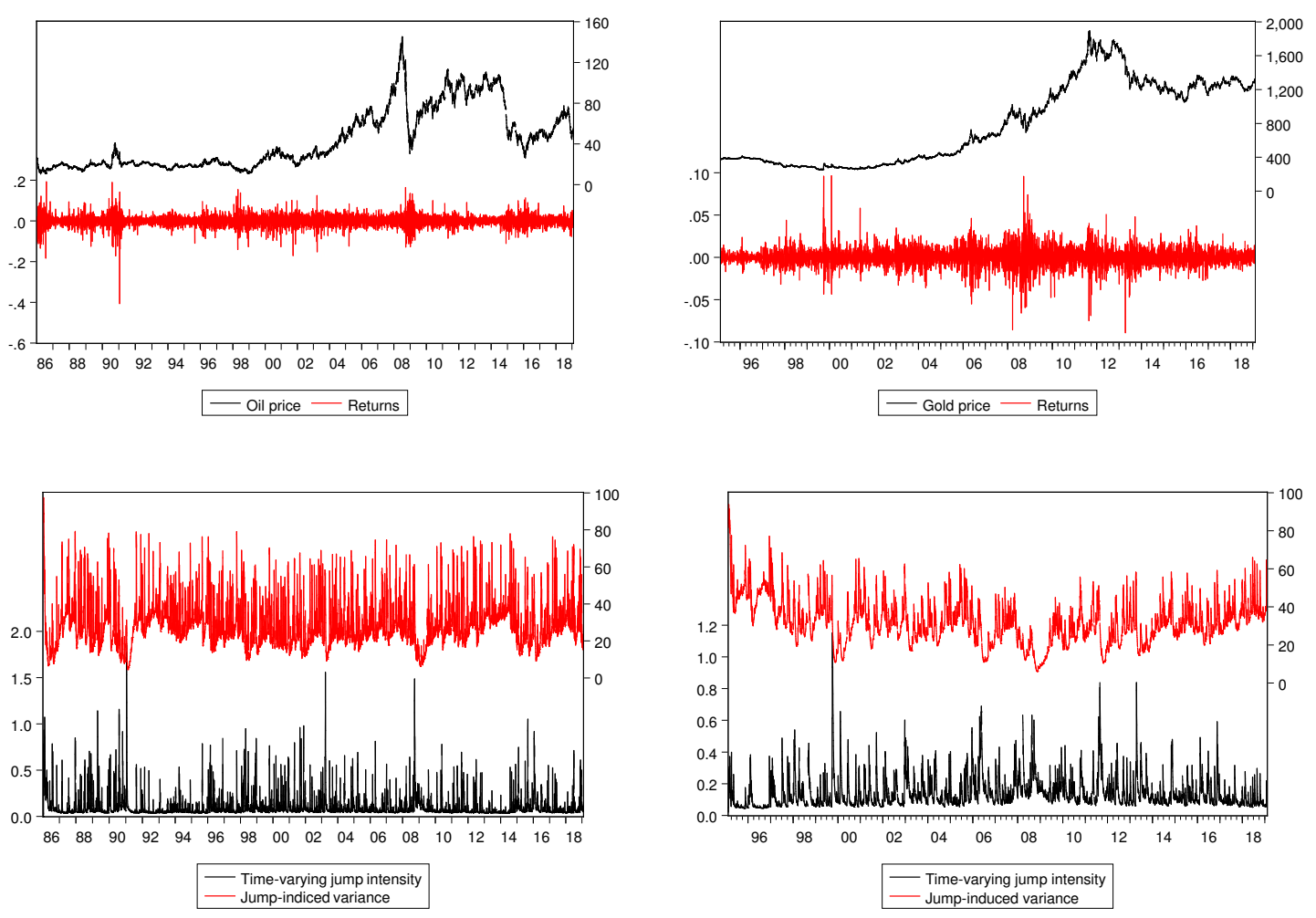

Figure 3: Comparison: Crude oil (left panel) and gold prices (right panel).

a smaller role. Shares of the jump-induced variance of about $60 \%$ as in the Bitcoin market are observed in the crude oil market in very early stages only - prior to 1986. In that period the crude oil market is considered very immature. The results for the gold market are overall similar: the jump component captures large gold price movements very well. In addition, the share of jump-induced variance fluctuates around $40 \%$, with a few declines to about $10 \%$. 


\section{Discussion}

As asserted above, the total number of Bitcoins is fixed - there are only 21 million units and "all of the quantities and growth rates of Bitcoins are known with certainty by the public" (Yermack, 2013). In addition, it is ensured that the growth rate of Bitcoins remains constant over time. These rules have been designed in advance by the creators of Bitcoin, without the intervention of any regulator, and will remain unchanged over time. The inflationary or deflationay risks associated with this have been addressed by various authors, epitomised by Yermack (2013): "In the case of a 'wild success' of Bitcoins and the replacement of sovereign fiat currency it would not be possible to increase the supply of Bitcoins in concert with economic growth."

This paper offers a novel interpretation of these very unique features: Not only Bitcoin is characterised by long-term fixed supply, but also exhaustible resource commodities such as crude oil and gold. There is, however, an important difference. In contrast to Bitcoin, where the current circulation is also known with certainty, current availability of oil is highly uncertain: OPEC announcements regarding their future oil production rates are usually followed with bated breath; whether or not OPEC countries will adjust production generally has considerable effects. Further complication stems from the high price-responsiveness of US shale production. Finally, new discoveries, new technological developments and even weather events and strikes on oil platforms complete the picture. It is remarkable that, even though the short-run supply of Bitcoin is not uncertain, the price movements 
in this market are even more extreme. This implies that the observed price jumps can only be caused by "demand-side" factors. As stated above, Ali et al.'s (2014) note that "digital currencies have meaning only to the extent that participants agree that they have meaning." This statement can also be expressed using commodity market terminology: A change in this "meaning" due to changes in demand is not different from a demand shock in the crude oil market. However, also the commodity market literature can learn from the analysis of Bitcoin: the consequences of a demand shock can be extraordinarily large.

\section{Conclusions}

The academic debate on Bitcoin has been dominated by the question whether Bitcoin is a currency or an asset. The conclusion reached to date is that Bitcoins are to be considered an asset or speculative investment rather than a currency. Yermack (2013) highlighted one of the main reasons: the fixed number of Bitcoins is a severe economic problem as the supply of money cannot be adjusted in concert with economic growth. Another reason why Bitcoin cannot function as money or currency is the observed price volatility. However, these types of conclusions leave open what Bitcoin actually is. This paper emphasises the similarities Bitcoin has with exhaustible commodity resources. As the latter are relatively well understood, both empirically and theoretically, this interpretation paves the way for the future analysis of Bitcoin.

The empirical analysis conducted in this paper finds that Bitcoin price 
dynamics are particularly influenced by extreme price movements. This influence is found to be larger than in the markets for crude oil and gold. Among the explanations for this is certainly the immaturity of the market. The unique market features discussed in this paper, however, also imply that there is no uncertainty on the supply-side and, thus, all extreme price movements can be interpreted as Bitcoin demand shocks.

\section{REFERENCES}

Ali, R., J. Barrdear, R.Clews and J. Southgate (2014). "The Economics of Digital Currencies", Bank of England Quartlery Bulletin 2014 Q3, 1-11

Baur, D.G., K.Hong And A.D.LeE (2018). "Bitcoin: Medium of exchange or speculative assets?", Journal of International Financial Markets, Institutions Money, 54: $177-189$

Camara, N., E. Dos Santos, F. Grippa, J. Sebastian, F. Soto and C. Varela (2018). "Central bank digital currencies: An assessment of their adoption in Latin America", BBVA Research Working Paper No18/13

Cheah, E.T. And J.Fry (2015). "Speculative Bubbles in Bitcoin markets? An Empirical Investigation into the Fundamental Value of Bitcoin", Economics Letters 130: $32-36$

Cheah, E.T., T.Mishra, M.Parhi And Z.Zhang (2018). "Long Memory Interdependency and Inefficiency in Bitcoin Markets", Economics Letters 167: 18-25

Chan, W.H. And J.M. Maheu (2002). "Conditional Jump Dynamics in Stock Market Returns", Journal of Business Economics and Statistics 20(3): 377-389

Corbet, S., B.Lucey, and L. Yarovaya (2018). "Datestamping the Bitcoin and Ethereum bubbles", Finance Research Letters 26: 81-88

Dowd, K. And M.Hutchinson (2015). "Bitcoin Will Bite the Dust", Cato Journal, 35(2): $357-382$

DyhrberG, A.H. (2016). "Hedging Capabilities of Bitcoin. Is it the Virtual Gold?", Finance Research Letters, 16: 139-144

DyhrberG, A.H., S.Foley And J.Svec (2018). "How investible is Bitcoin? Analyzing the Liquidity and Transaction Costs of Bitcoin Markets", Economics Letters, 171: 140-143

Engert W. And B.S.C. Fung (2017). "Central Bank Digital Currency: Motivations and Implications", Bank of Canada Staff Discussion Paper 2017-16

Engle, R.F. And T.Bollerslev (1996). "Modelling the Persistence of Conditional Variances", Econometric Reviews 5: 1-50 
Fernandez-Villaverde, J. And D.Sanches (2016). "Can Currency Competition work?", NBER Working Paper Series 22157

Glosten, L.R., R.Jagannathan, and D.E. Runkle (1993). "On the Relation between the Expected Value and the Volatility of the Nominal Excess Return on Stocks", The Journal of Finance 48(5): 1779-1801

Gronwald, M. (2012). "A Characterization of Oil Price Behavior Evidence from Jump Models", Energy Economics 34,1310-1317

HAYEK, F.A. (1976). "Choice in Currency", The Institute of Economic Affairs, London

Henriques, I. And P.SAdorsky (2018). "Can Bitcoin Replace Gold in an Investment Portfolio?", Journal of Risk and Financial Management 48: doi:10.3390/jrfm11030048

Jorion, P.. (1988). "On Jump Processes in the Foreign Exchange and Stock Markets", Review of Financial Studies 1,427-445

Katsiampa, P. (2017). "Volatility estimation for Bitcoin: A comparison of GARCH models", Economics Letters 158: 3-6

Keister, K. And D. Sanches (2018). "Should Central Banks issue Digital Currency?", unpublished manuscript, available at http://www . toddkeister.net/pdf/KS_CBDC.pdf

Khuntia, S. And J.K. Pattanayak (2018). "Adaptive Market Hypothesis and Evolving Predictability of Bitcoin", Economics Letters, 167: 26-28

Kumhof, M. And C.Noone (2018). "Central Bank Digital Currencies Design Principles and Balance Sheet Implications", Bank of England Staff Working Paper No 725 .

Nakamoto, S. (2008). "Bitcoin: A Peer-to-Peer Electronic Cash System", unpublished manuscript, available at https://bitcoin.org/bitcoin.pdf

Nelson, D.B.. (1991). "Conditional Heteroscedasticity in Asset Returns: a New Approach", Econometrica 59: 347-370

Nimalendran, M. (1994). "Estimating the Effects of Information Surprises and Trading on Stock Returns using a Mixed Jump-Diffusion Model", The Review of Financial Studies 7: 451-473

Phillip, A., J.S.K Chan And S. Peiris (2018). "A new Look at Cryptocurrencies", Economic Letters 163: 6-9

Sanin, M.E., F.Violante and M. Mansanet-Bataller (2015). "Understanding Volatility Dynamics in the EU-ETS Market", Energy Policy 82: 321-331

SAnches, D. (2016). "On the Inherent Instability of Private Money", Review of Economic Dynamics, 20: 198-214

SAnches, D. (2018). "Bitcoin vs. The Buck: is Currency Competition a Good Thing?", Federal Reserve Bank of Philadelphia Research Department Working Paper, 2018 $\mathrm{Q} 2$

Shen, D., A. Urquhart and P.Wang (2019). "Does twitter predict Bitcoin?", Economics Letters 174: 118-122

Urquhart, A. (2016). "The Inefficiency of Bitcoin", Economics Letters 148: 80-82

Urquhart, A. (2018). "What causes the Attention of Bitcoin?", Economics Letters 166: $40-44$ 
Yermack, M. (2013). "Is Bitcoin a Real Currency", NBER Working Paper 19747

Yi, S., Z. XU, AND G.-J. WANG (2018). "Volatility Connectedness in the Cryptocurrency Market: Is Bitcoin a dominant Cryptocurrency?", International Review of Financial Analysis, doi:10.1016/j.irfa.2018.08.012

\section{A Online Appendix: Detailed estimation Results for oil And GOLD PRICES}

This appendix presents detailed estimation results for oil and gold prices. The model comparison presented in Table A1 shows that the results are overall similar to Bitcoin. The $\operatorname{GARCH}(1,1)$ with student- $t$ innovations as well as the jump models generally perform better than the remaining models. However, the relative improvement in performance appears to be smaller. In addition, there seems to be some evidence of leverage effects. The asymmetric models slightly outperform the basic models but cannot compete with the best performing models.

\section{B Online APPENDIX: EMPIRICAL MODELS}

The price behaviour of Bitcoin returns is analysed using a number of both linear and non-linear GARCH models. A standard GARCH $(1,1)$ model serves as the benchmark:

$$
\begin{aligned}
y_{t} & =\mu+\sum_{i=1}^{l} \phi_{i} y_{t-i}+\epsilon_{t} \\
\epsilon_{t} & =\sqrt{h_{t}} z_{t} \\
h_{t} & =\omega+\alpha \epsilon_{t-1}^{2}+\beta h_{t-1}
\end{aligned}
$$

with $y_{t}$ denoting Bitcoin price returns. ${ }^{11}$ Gaussian as well as student- $t$ innovations are considered. In addition to testing the restriction $\alpha+\beta=$ 1 (IGARCH, see Engle and Bollerslev, 1986) a number of extensions are used. $^{12}$ As a common feature of various financial market variables is an asymmetric response to negative and positive news, the TGARCH model proposed by Glosten et al. (1993) is useful. The conditional variance is then written as

\footnotetext{
${ }^{11}$ The number of autoregressive parameters is selected using standard Information Criteria.

${ }^{12}$ All extensions use Gaussian innovations only.
} 


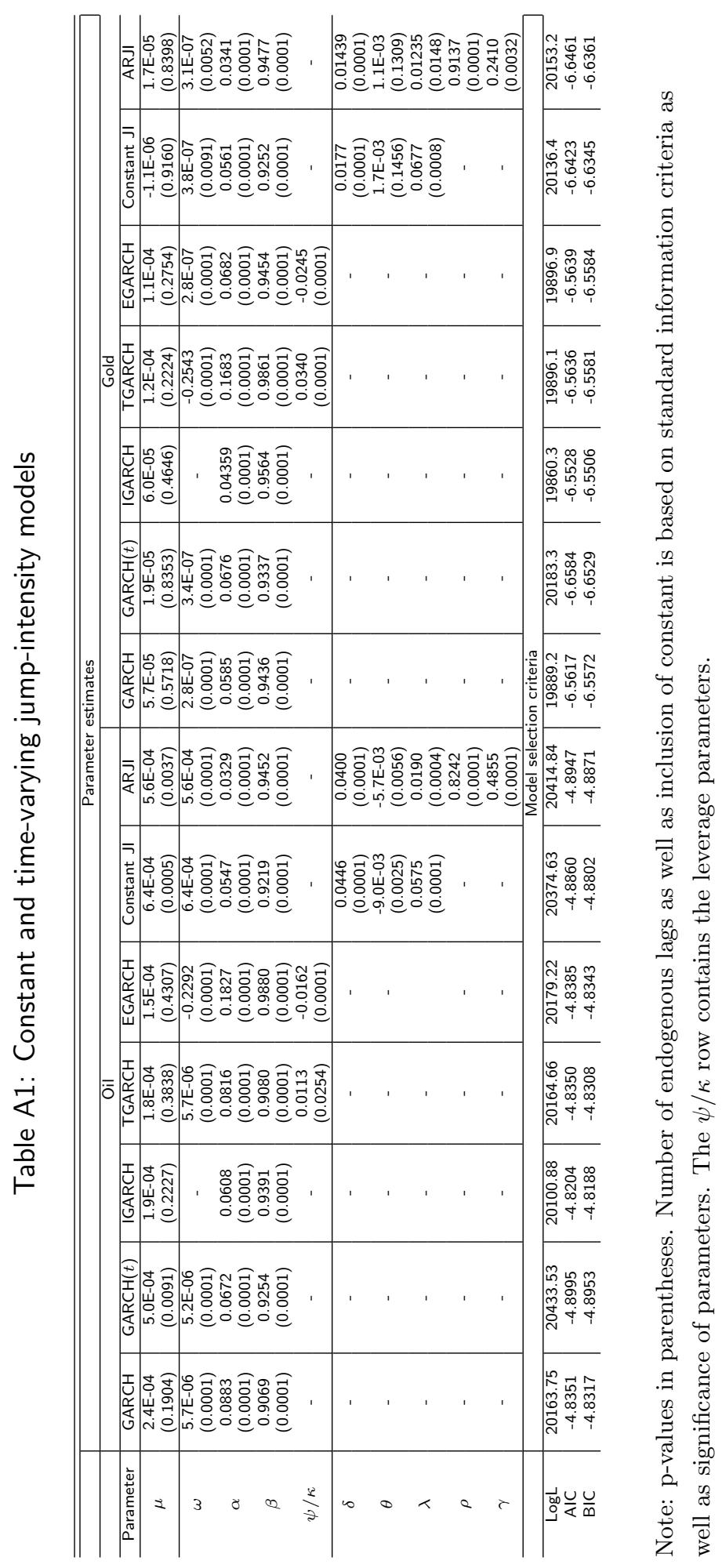




$$
h_{t}=\omega+\alpha \epsilon_{t-1}^{2}+\beta h_{t-1}+\psi \epsilon_{t-1}^{2} I_{t-1}
$$

where $I_{t}=1$ if $\epsilon_{t}<0$. In order to test if the leverage effect is exponential, the EGARCH model proposed by Nelson (1991) is also used:

$$
\log \left(h_{t}\right)=\omega+\alpha\left|\frac{\epsilon_{t-1}}{\sqrt{h_{t-1}^{2}}}\right|+\beta \log \left(h_{t-1}\right)+\kappa \frac{\epsilon_{t-1}}{\sqrt{h_{t-1}^{2}}}
$$

The presence of leverage effects can be tested using the following hypothesis: $\kappa<0$.

A number of recent papers also point out that certain commodity prices are not only characterized by conditional heteroscedastcity but also by jumps: Gronwald (2012) as well as Lee et al (2012) find evidence of jumps in crude oil prices, Sanin et al (2015) in European carbon prices. These markets are generally considered "political" markets subject to various types of influences. The European carbon market, in addition, is also a newly established market. Jumps in commodity prices are generally considered reflecting reactions of prices to surprising news; see e.g. Jorion (1988). In order to analyse the role of extreme price movements in the Bitcoin market, the so-called autoregressive jump-intensity GARCH model proposed by Chan and Maheu (2002) is used. The benchmark model B is rewritten as follows:

$$
y_{t}=\mu+\sum_{i=1}^{l} \phi_{i} y_{t-i}+\sqrt{h_{t}} z_{t}+\sum_{k=1}^{n_{t}} X_{t, k}
$$

where $h_{t}$ is still described by the $\operatorname{GARCH}(1,1)$ process $h_{t}=\omega+\alpha \epsilon_{t-1}^{2}+$ $\beta h_{t-1}$.

The last term in Equation B denotes the jump component. It is assumed that the (conditional) jump size $X_{t, k}$ is normally distributed with mean $\theta_{t}$ and variance $\eta_{t}^{2} ; n_{t}$ describes the number of jumps that arrive between $t-1$ and $t$ and follows a Poisson distribution with $\lambda_{t}>0$ :

$$
P\left(n_{t}=j \mid \Phi_{t-i}\right)=\frac{\lambda_{t}^{j}}{j !} e^{-\lambda_{t}}
$$

$\lambda_{t}$ is called jump-intensity. The model is estimated in two variants: a constant jump-intensity model with $\lambda_{t}=\lambda, \theta_{t}=\theta$, and $\eta_{t}^{2}=\eta^{2}$ and a timevarying jump-intensity model. For the latter, $\lambda_{t}$ is assumed to follow the 
auto-regressive process

$$
\lambda_{t}=\lambda_{0}+\sum_{i=1}^{r} \rho_{i} \lambda_{t-i}+\sum_{i=1}^{s} \gamma_{i} \xi_{t-i} .
$$

The application of the time-varying jump intensity model allows one to study how the influence of extreme price movements changes over time. According to Nimalendran (1994), finally, the total variance $\Sigma^{2}$ of a process can be decomposed in a jump-induced part and a diffusion-induced part:

$$
\Sigma^{2}=h_{t}+\lambda_{t}\left(\theta^{2}+\eta^{2}\right) .
$$

This decomposition procedure allows one to compare statistical behaviour across different markets. Finally, calculating this measure using the timevarying jump intensity makes possible to study how the share of jumpinduced variance changes over time. 